\title{
Observations of Wind Forcing Effects on Estuary Length and Salinity Flux in a River-Dominated, Microtidal Estuary, Mobile Bay, Alabama
}

\author{
JEFFREY COOGAN AND BRIAN DZWONKOWSKI \\ University of South Alabama, Mobile, and Dauphin Island Sea Lab, Dauphin Island, Alabama
}

(Manuscript received 28 November 2017, in final form 6 June 2018)

\begin{abstract}
Using long-term records ( 11 years) of salinity and 390 days of ADCP data, aspects of the estuary length and salinity flux were evaluated in Mobile Bay under a range of river discharge, tidal, and wind conditions. The temporal variability in the salinity structure was represented by the estuary length and showed a relationship of $Q_{R}^{-1 / 7}$ with respect to river forcing, similar to values reported in San Francisco Bay and Delaware Bay. Local wind forcing was observed to play a role in modifying this $Q_{R}^{-1 / 7}$ relationship, in which estuary length responded asymmetrically to along-channel winds with up-estuary winds, reducing the estuary length. To further explore potential salinity transport changes associated with the wind, a 1D salinity flux was calculated using the ADCP and salinity profile data. River discharge was the main forcing condition driving seasonal changes in salinity flux. At shorter time scales, the wind became a dominant forcing condition and drove large changes in the salinity flux during low-discharge periods. At all discharge levels, down-estuary wind conditions enhanced the shear and subtidal exchange. During up-estuary wind conditions, the two-layer flow was inhibited and reduced the exchange. These results indicate that in a shallow microtidal system, wind can play a large role in modifying the estuary length on scales comparable to the spring-neap changes observed in other systems.
\end{abstract}

\section{Introduction}

Understanding the salt balance in estuaries is an important process to examine how the salinity structure responds to river, wind, and tidal forcing on subtidal time scales. This dynamic relationship among salinity structure, forcing conditions, and feedbacks can be broken into river forcing, baroclinic exchange, and mixing components. From this simple balance, researchers have been able to describe the salt storage of a system and how the salinity structure and estuary length are expected to respond. An ideal steady-state relationship was described based on this balance by Monismith et al. (2002) and further parameterized by Ralston et al. (2008) to show estuary length is proportional to

$$
L_{x} \sim \frac{\left(\beta g S_{0}\right)^{2 / 3} A^{1 / 3} H^{5 / 3}}{\gamma Q_{R}^{1 / 3} U_{t}},
$$

where $A$ and $H$ are the cross-sectional area and depth, $\beta$ and $S_{0}$ are the saline contraction coefficient and depthaveraged salinity at the ocean end of the estuary, $U_{t}$ is

\footnotetext{
Corresponding author: Jeffrey Coogan, jcoogan@disl.org
}

the tidal velocity amplitude, and $\gamma$ represents a vertical mixing parameterization. This ideal steady-state solution can be further simplified to represent the classic $L_{x} \sim Q_{R}^{-1 / 3}$ relationship, where estuary length has a $1 / 3$ power dependence on river discharge. This river discharge to estuary length relationship has been examined in several systems: Delaware Bay (Garvine et al. 1992), San Francisco Bay (Monismith et al. 2002), and the Hudson River (Abood 1974).

Though the ideal relationship holds the mixing parameterization constant, it should be noted that in Eq. (1), estuary length is more sensitive to mixing $\gamma^{-1}$ than river forcing $Q_{R}^{-1 / 3}$. Hetland and Geyer (2004) examined this parameter space for a range of mixing and discharge conditions, showing that estuary length varied with changing mixing rates in their idealized modeled system. Recent research has put forth additional mechanisms of forcing that drive exchange and mixing through tidal straining, lateral advection, and along-channel wind forcing. MacCready and Geyer (2010) proposed that with this increased understanding of the complex interactions among turbulence, stratification, and advection, a new set of mixing parameterizations can be defined. The estuary length relationship, though simple, has a 
high sensitivity to mixing and with this provides an opportunity to improve our understanding of how variability in mixing can impact estuarine systems. The parameterization of mixing through eddy viscosity and eddy diffusivity is an important area of focus for tidally averaged models. Though previous work has focused on tidal mixing, changes in $\gamma$ as a function of discharge or stratification will potentially impact estuary length with the same sensitivity. In Delaware Bay, a less than $Q_{R}^{-1 / 3}$ length relationship was observed by Aristizábal and Chant (2013). Their model showed the vertical eddy viscosity was reduced by half with increases in discharge and suggested this change in viscosity played an important role in controlling the salt intrusion. During periods of variable mixing and discharge, the steady-state assumption for Eq. (1) may no longer be satisfied, and these changes in the salt budget can be examined by

$$
\frac{d}{d t} \int \bar{s} d x=-\bar{u} \bar{s}-\overline{\left(u^{\prime} s^{\prime}\right)}+K_{H x} \bar{s}_{x},
$$

where overbars denote depth-averaged salinity $s$ and velocity $u$; primes are vertical deviations from the depthaveraged velocity and salinity; $K_{H}$ is the horizontal diffusion; $t$ is time; $x$ is along-estuary distance; and $\bar{s}_{x}$ is the along-estuary salinity gradient. On the right-hand side of Eq. (2), the three terms account for the salinity flux through advection, exchange associated with vertical variability in salt and shear, and the tidal oscillatory salt flux. Lerczak et al. (2006) examined the components of Eq. (2) and found that the Hudson River estuary was never in a steady state. The advective and exchange salt fluxes did not balance due to changes associated with the spring-neap cycle in that system. Kim and Park (2012) examined the salt flux with Eq. (2) as well but focused on the mouth of Mobile Bay. The authors observed changes in stratification associated with river discharge that led to large variability in the salt flux parameters over tropic-equatorial changes (similar to spring-neap cycle). During high discharge, the exchange flux varied by an order of magnitude between the tropic and equatorial tides, and during equatorial tides, the exchange exceeded the advective flux driving a net increase of salt into the estuary.

In addition to discharge and tidal variability, wind has also been observed and modeled as an important driver of salinity structure and mixing in estuarine systems. The mechanisms of along-channel winds modifying and inhibiting exchange have been described by numerous researchers (Geyer 1997; Scully et al. 2005; Chen and Sanford 2009; Li and Li 2011). Work by Ralston et al. (2008, p. 755) saw "meteorological band fluctuations in forcing significantly impacted residual velocities and salinity distribution." Their model, though, was limited to wind-driven changes using the HansenRattray solution. Scully et al. (2005) described the mechanisms of along-channel winds that could modify (inhibit) the exchange flow during down- (up) estuary winds and through straining the along-channel density gradient. Chen and Sanford (2009) further refined the roles of wind modifying or inhibiting exchange by defining the percentage of the water column affected by direct wind mixing. This mixing constrained the impact that down-estuary winds had on enhancing stratification. The net salt flux associated with these winds was observed in the subtidal shear dispersion term. During moderate down-estuary winds, the subtidal shear dispersion was enhanced, but limited by how much of the water column was affected by direct wind mixing as down-estuary wind speeds increased. During up-estuary winds, the subtidal shear dispersion was always reduced by the winds. Li and Li (2011) also observed asymmetry in the estuary response to along-channel winds. Their modeled stratification and salt flux changes were observed to take longer to recover after the up-estuary wind conditions. After a down-estuary wind event, changes in stratification recovered shortly after the wind event ended, but stratification took 1-3 weeks to recover after an up-estuary wind event.

The impact of wind on exchange and recovery has been observed primarily in idealized model scenarios or over short temporal wind events. Observations from this study attempt to highlight the importance of this previous research and understand the complex interactions occurring in Mobile Bay. The focus of this work is to present evidence of wind forcing effects on estuary length. Salinity flux observations are presented to provide further insight on how the system is changing from these wind effects and the complexity of this response associated with changing river discharge in Mobile Bay.

\section{Mobile Bay}

Mobile Bay is a large drowned river valley in the northern Gulf of Mexico. Like most of the estuaries in the northern gulf, the bay has a microtidal range and high river discharge, and it is wide and shallow with a deep narrow shipping channel running the length of the bay (Schroeder and Wiseman 1999). The diurnal microtide in Mobile Bay ranges from $<0.1 \mathrm{~m}$ during equatorial tides to $0.8 \mathrm{~m}$ during tropic tides. This tropicequatorial cycle (13.66 days) is similar to the springneap cycle (14.76 days) and is a result of the $\mathrm{K}_{1}$ and $\mathrm{O}_{1}$ tidal constitutions (as opposed to the $\mathrm{M}_{2}$ and $\mathrm{S}_{2}$ during spring-neap) moving in and out of phase (Kim and Park 2012). Figure 1 shows the relatively uniform bathymetry throughout the bay with an average depth of $3 \mathrm{~m}$. 


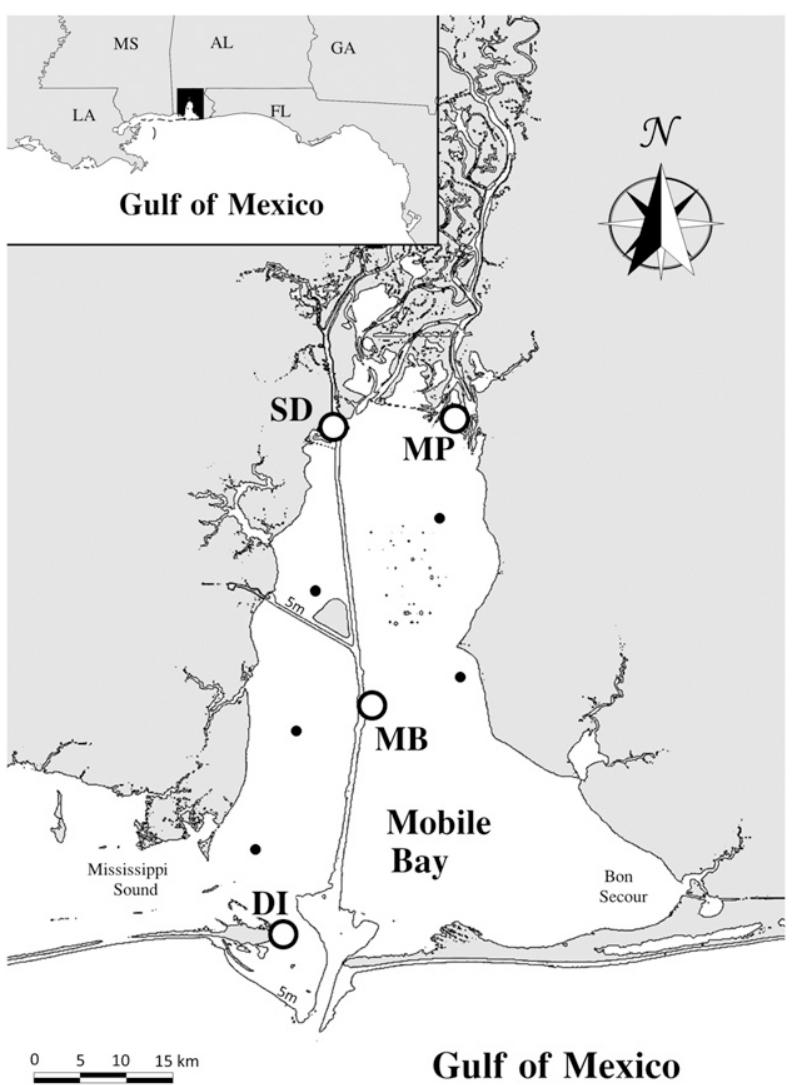

FIG. 1. Map of Mobile Bay and the location of the three water quality stations DI, MB, and MP. Stations SD and DI measure water level. Smaller black dots indicate the five additional stations used to validate the estuary length method. The 5-m depth contour is shown to highlight the shallow uniform bathymetry of the bay and deep central shipping channel that runs the length of the bay.

The exception to this is the deep $(12 \mathrm{~m})$ but narrow $(120 \mathrm{~m})$ shipping channel that runs the length of Mobile Bay. Average discharge into the bay during the study period was $1400 \mathrm{~m}^{3} \mathrm{~s}^{-1}$. Figure 2 highlights the river discharge variability that peaks in the spring with discharge up to $7000 \mathrm{~m}^{3} \mathrm{~s}^{-1}$ and falls to less than $500 \mathrm{~m}^{3} \mathrm{~s}^{-1}$ throughout the summer and early fall.

Previous research has highlighted the importance of wind in this broad shallow system. Stratification and destratification events are not dependent on springneap cycles as is common in other systems, but instead wind-induced mixing and river discharge drive the variability in stratification (Schroeder et al. 1990; Park et al. 2007; Kim and Park 2012). Noble et al. (1996) observed the estuary as being highly stratified $\left(5 \mathrm{PSU} \mathrm{m}^{-1}\right.$ were commonly observed), and resistant to mixing $80 \%$ of the time. The observed currents were also highly sheared $\left(0.08 \mathrm{~s}^{-1}\right)$ when the system was stratified. These strong

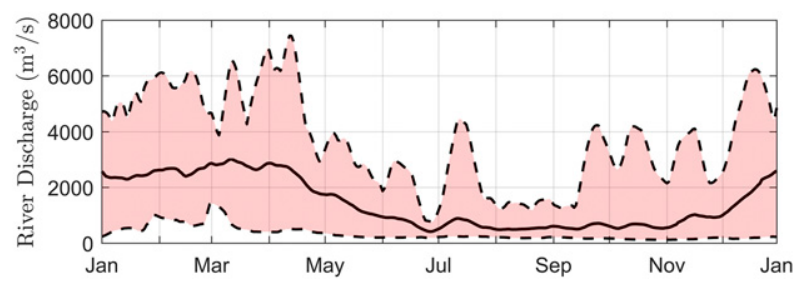

FIG. 2. The 14-day average annual discharge into Mobile Bay from 2005 to 2016 is shown in black. Discharge was measured using two upstream USGS stations on the Tombigbee and Alabama Rivers. The red-shaded regions highlight the max and min variability during this 11-yr period.

vertical density gradients in Mobile Bay are not easily broken down by the wind. Winter wind events can produce mixing power $6-8$ times greater than the rootmean-square tidal current-driven mixing (Schroeder et al. 1990). Fall and winter are dominated by winds out of the north (down estuary) 39\% of the time, and spring is more variable, with winds out of the north $21 \%$ of the time and out of the south (up estuary) $31 \%$ of the time. In summer, low winds are persistent and are less than $5 \mathrm{~m} \mathrm{~s}^{-1} 48 \%$ of the time. The bay responds strongly to along-channel wind events that are effective in altering water levels in the shallow upper bay and changing the barotropic pressure gradient that drives the mean flow (Schroeder and Wiseman 1986). These physical characteristics associated with shear and stratification make Mobile Bay an ideal place to measure and observe how winds can drive the salinity structure in an estuary system.

\section{Data and methods}

\section{a. Data sources}

Long-term monitoring data from Mobile Bay were used to examine the salinity structure and estuary length in the bay. The three long-term monitoring stations, highlighted in Fig. 1, were DI at the estuary mouth, MB at the center of the bay, and MP at the northern end of bay. Temperature and salinity data were collected using YSI 6600s with sampling frequencies at half-hour and hour intervals. Data collection began in 2005 and is still ongoing. The longest data gap occurred for 9 months out of the 11-yr record. MP and DI were fixed, near-bottom stations, and MB was a vertical profiler sampling at $0.5-\mathrm{m}$ intervals. In addition to these three stations, five fixed, near-bottom stations were deployed, and 1 year of data from 1 August 2015 to 1 August 2016 were used to validate observations from the three long-term stations. These data were also collected using YSI 6600s with sampling frequencies of $15 \mathrm{~min}$. 
Wind data were collected at the MB station (Fig. 1) from a height of $14.2 \mathrm{~m}$ above mean lower low water (MLLW) at 1-min intervals and averaged to $48 \mathrm{~h}$ for analysis. Up-estuary winds (northward) are defined as positive, and down-estuary winds (southward) are negative.

A $1200-\mathrm{kHz}$ RDI Workhorse Monitor ADCP was bottom mounted at the MB station from April 2012 to June 2014 to collect current data. The location of the ADCP was roughly $15 \mathrm{~m}$ from the profiler measuring salinity and temperature near the side of the channel. Over the course of the 2-yr deployment, a total of 390 days of data were collected. The largest gap in data occurred over 280 days. The ADCP collected $0.5-\mathrm{m}$ bin data at 10 -min intervals comprising 60 pings at 2 -s intervals. Initial postprocessing eliminated all error velocities greater than $0.1 \mathrm{~m} \mathrm{~s}^{-1}$, which was $7 \%$ of the data. No coordinate transformation was performed since the along-channel velocity and north/south velocities already are in alignment with the principal component. These data were then averaged to hourly intervals for the salinity flux and conditional averaging analysis.

To qualitatively evaluate the significance of alongchannel winds and river discharge on current profiles, a conditional average was examined. Current profiles were chosen based on threshold wind conditions and threshold river discharge values. Threshold river discharge values were $Q_{R} \geq 1450 \mathrm{~m}^{3} \mathrm{~s}^{-1}$ (values greater than the average discharge in Mobile Bay) and $Q_{R}<$ $1450 \mathrm{~m}^{3} \mathrm{~s}^{-1}$ (values less than the average discharge). Threshold wind conditions were determined over 48-h periods, during which the wind direction was between $310^{\circ}$ and $50^{\circ}$ for $70 \%$ of the time (up-estuary conditions), between $130^{\circ}$ and $230^{\circ}$ for $70 \%$ of the time (down-estuary conditions), or any direction with wind velocities $<5 \mathrm{~m} \mathrm{~s}^{-1}$ for $80 \%$ of the time (calm conditions). Current profiles that met the threshold conditions were averaged together. The lowest sample size of this conditionally averaged data used 441 profiles to calculate the average profile.

River discharge data were calculated based on two USGS gauging stations: the Claiborne L\&D (USGS station 02428401) on the Alabama River and Coffeeville L\&D (USGS station 02469762) on the Tombigbee River stations. The sum river flow of the two stations was used as the total river discharge into Mobile Bay, following Park et al. (2007).

\section{b. Calculating estuary length}

To study estuary length in Mobile Bay, a linear interpolation of the three long-term monitoring stations, DI, MB, and MP (Fig. 1), was used to estimate the location of the 6-PSU contour. The 6-PSU contour was chosen for the estuary length to be a value near zero, but also to be large enough to maximize the number of observations available for the MP station. Estuary length was calculated based on 14-day average salinity values from the water quality time series data. The 14-day average was chosen to average out the tropic-equatorial tidal variability. Data points covered 11 years, from 2005 to 2016.

To validate the low-spatial-resolution method of only using three stations, 1 year of data that included eight stations throughout the bay (the five additional stations are shown as black dots in Fig. 1) were used to examine the variability in solving for estuary length. An average difference of $9 \%$ and a standard deviation of $15 \%$ difference were observed when comparing estuary length calculations using three and eight stations. The lowspatial-resolution method works well in Mobile Bay as a result of the 14-day average time period and relatively uniform bathymetry in the bay. Sensitivity analysis of the low- and high-resolution methods showed there was increasing standard deviation between the two measurements with temporal averages shorter than 11 days.

Other more involved methods have been used to calculate estuary length in San Francisco Bay (Monismith et al. 2002) and the Hudson (Lerczak et al. 2009). These studies highlight the along-estuary salinity structure as being linear when $S$ is scaled by $S_{o}$, and $x$ (the alongestuary location of $S$ ) is scaled by the estuary length $L$. This self-similarity can be used to validate the use of a fixed-station approach to measuring the estuary length. This condition was not always met for Mobile Bay, but both Monismith et al. (2002) and Lerczak et al. (2009) observed that the largest changes from their linear selfsimilarity trend occurred during high discharge. The limit of using a fixed station for nonlinear self-similarity means that as $x / L$ increases faster than $S / S_{o}$ with increasing discharge, the length to river relationship is likely to be less sensitive than observed. This translates to the estuary length in the bay shortening, but mixing at the ocean end does not occur at a quick enough rate, resulting in the estuary length growing at the offshore end of the bay (out of the estuary). Additional analysis of low-discharge periods in Mobile Bay that fell within the linear self-similarity region showed a smaller, less sensitive $L-Q_{R}$ relationship than those observed in this study and suggested the length to discharge relationships are likely smaller than those reported in the results. The focus of this work, though, was on the wind's impact and deviations from the best fit line with respect to wind. This best fit line accounts for the nonlinear changes in the $S / S_{o}$ and $x / L$ relationships, and the measured impacts of wind on the system represent accurately the changes occurring in the system. 
The estuary length observations in Mobile Bay exceed the upper and lower bounds of the water quality stations. During discharges $>3600 \mathrm{~m}^{3} \mathrm{~s}^{-1}$, freshets events were observed and resulted in the DI station dropping below 6 PSU. This occurred 10 days out of the year, on average. Additionally, during periods of discharge $<450 \mathrm{~m}^{3} \mathrm{~s}^{-1}$, the MP station salinity could exceed 6 PSU, and this occurred 30 days total throughout the year. These time periods were not included in the final estuary length dataset. It should also be noted that the estuary length examined in this paper represents a baywide average. Salinity intrusion in the deep $(12 \mathrm{~m})$ but narrow $(120 \mathrm{~m})$ channel always exceeds these baywide average estuary lengths, but the channel represents a small portion of the overall bay shape (Fig. 1).

\section{c. Calculating salinity flux}

The salinity flux in Mobile Bay was evaluated at the MB station based on methods outlined in Lerczak et al. (2006) and simplified to solve for a 1D estimate of salt transport. Following Lerczak et al. (2006) and Kim and Park (2012), the salt flux per unit width was decomposed into three components, using

$F_{S}=\left\langle\int u S d z\right\rangle$,

$F_{S}=\left\langle\int\left(u_{o}+u_{E}+u_{T}\right)\left(S_{o}+S_{E}+S_{T}\right) d z\right\rangle, \quad$ and

$F_{S} \approx\left(F_{A}+F_{E}+F_{T}\right)$,

where $u_{o}$ and $S_{o}$ are the depth-averaged, 48-h, low-passfiltered velocity and salinity; $u_{E}$ and $S_{E}$ are the exchange components; $u_{T}$ and $S_{T}$ are the hourly velocity and salinity tidal deviations from the 48-h low-pass data; and the angled brackets indicate a 48-h low-pass filter. The salinity flux components are the advective flux $F_{A}$, the exchange flux $F_{E}$, and the tidal oscillatory salt transport $F_{T}$. The total flux $F_{S}$ is per unit width at this cross-section of Mobile Bay. The $F_{E}$ component for this 1D approach does not resolve variability associated with the lateral shear or lateral shear dispersion. Though this limits the potential analysis of the data, the method provides a reasonable first-order estimate for the salinity flux in this highly stratified estuary.

To estimate the potential lateral shear across the estuary, a lateral shear proxy was solved for based on the depth-averaged flow measured by the ADCP and compared with a theoretical depth-averaged flow based on continuity. The theoretical flow was solved using

$$
0=\frac{d V}{d t}+A_{\mathrm{MB}} U_{\text {theory }}+Q_{R},
$$

where $d V / d t$ is the 48-h low-pass-filtered change in volume for the upper bay between stations MB and SD
(Fig. 1); $Q_{R}$ equals flow into the system from river discharge; and flow out is the cross-sectional area $\left(A_{\mathrm{MB}}\right)$ at station MB (east-west) times the depth-averaged flow $\left(U_{\text {theory }}\right)$. The volume change was estimated using water level data from the NOAA tide station at DI (8735180) and SD (Mobile State Docks; 8737048) located at the southern and northern ends of Mobile Bay. Water level was assumed to be linear between the NOAA stations. This assumption was validated using the ADCP water level and had a standard deviation of $0.11 \mathrm{~m}$. The water volume was calculated using the area from the NOAA nation centers for environmental information estuary DEM data with a $30-\mathrm{m}$ resolution, and it was assumed setup and set down north of the SD station was negligible. A 3.5-day lag was applied to the river discharge $\left[Q_{R}\right.$ in Eq. (6)] to account for the time it takes the discharge to reach Mobile Bay from the USGS stations located $100 \mathrm{~km}$ upstream. This lag was determined based on a crosscorrelation between the depth-averaged flow at MB and river discharge. The $U_{\text {theory }}$ was compared to depth-averaged observations from the ADCP at station $\mathrm{MB}$ to estimate the lateral shear for this region of Mobile Bay. Larger differences between $U_{\text {theory }}$ velocities and ADCP depth-averaged velocities indicate potential lateral exchange.

From the 390 days of ADCP and salinity data, profiles for $u$ and $S$ were extrapolated to the surface and bottom to provide estimates over the entire water column. Nearbottom currents were extrapolated from the last bin to the seafloor $(0.62 \mathrm{~m})$ using a linear fit to a no-slip condition at the seafloor. The linear fit was chosen over a log-layer fit because some profiles were not within the bottom boundary layer in this shallow, highly stratified, and sheared environment. Near the surface, currents were fit to a parabola with a no-shear condition at the surface for the upper $30 \%$ of the water column to account for noise and sidelobe interference. Salinity profile data were also extrapolated to the surface and bottom, where the profiler stopped sampling approximately $1.5 \mathrm{~m}$ from the bottom and $0.5 \mathrm{~m}$ from the surface. A parabolic fit using a no-flux condition was used near the bottom, and at the surface, salinity values were held constant for the upper half meter of the water column.

\section{d. Mixing and straining}

Estuary length and salinity flux were further analyzed with nondimensional numbers to understand wind forcing and mixing impacts on the system. The dynamics between wind stress and the baroclinic pressure gradient were evaluated by the Wedderburn number (Monismith 1986; Chen and Sanford 2009): 


$$
W=\frac{\tau_{w x} L}{\Delta \rho g H^{2}},
$$

where $\tau_{w x}$ is the along-channel wind stress (positive values are up-estuary wind stress), $L$ is the length of the estuary $(48 \mathrm{~km}), \Delta \rho$ is the density change over the estuary length, and $H$ is the average water depth $(3 \mathrm{~m})$.

In addition to the Wedderburn number, sheared advection of salt and vertical mixing was examined using a modified horizontal Richardson number (Chen and Sanford 2009). Stacey et al. (2001) used the vertical derivative salt transport equation

$$
\frac{\partial}{\partial t}\left(\frac{\partial s}{\partial z}\right)+\frac{\partial U}{\partial z} \frac{\partial s}{\partial x}=\frac{\partial^{2}}{\partial z^{2}}\left(K_{S} \frac{\partial s}{\partial z}\right)
$$

to show that the stratifying effects from sheared horizontal advection of along-channel salt $[(\partial U / \partial z)(\partial s / \partial x)]$ and vertical mixing $\left\{\partial^{2} / \partial z^{2}\left[K_{S}(\partial s / \partial z)\right]\right\}$ come into balance to define the changes in stratification that occur in an estuary as the horizontal Richardson number

$$
\mathrm{Ri}_{x}=\frac{H^{2} N_{x}^{2}}{u_{*}^{2}},
$$

where $H$ is the water depth, $N_{x}^{2}$ is the horizontal buoyancy frequency $[-g \beta(\partial s / \partial x)]$, and $u_{*}$ is the bottom friction velocity $\left(\sqrt{C_{D}} U_{t}\right)$. Chen and Sanford (2009) further developed this relationship between stratifying and mixing components to include the role of the wind in modifying the sheared horizontal advection and vertical mixing to develop a modified horizontal Richardson number:

$$
\mathrm{Ri}_{x, \text { new }}=\frac{\left(H^{4} N_{x}^{4} / 48 K_{M}\right)(1-a W)}{R_{f}\left(U_{*_{s}}^{3} / k h_{s}+U_{*_{b}}^{3} / k h_{b}\right)},
$$

where $R_{f}$ is the flux Richardson number $(0.2), U_{*_{s}}$ is the friction velocity near the surface $\left(\sqrt{\tau_{w x} \rho}\right), k$ is von Kármán constant (0.41), $K_{M}$ is the eddy viscosity, $h_{s}$ and $h_{b}$ are the bottom and surface boundary layer thickness, and $a$ is a scaling constant (12). Eddy viscosity is parameterized following MacCready (2007) as

$$
K_{M}=A_{o} H C_{D} U_{T},
$$

where $A_{o}$ is the effective eddy viscosity (0.054). Parameters $h_{b}$ and $h_{s}$ are estimated following Chant et al. (2007), Chen and Sanford (2009), and Trowbridge (1992) by an entrainment model,

$$
h_{s, b}=\sqrt{2 \gamma \operatorname{Ri}_{c}^{1 / 2} \frac{u_{*, b}^{2}}{N_{\infty}} \Delta t},
$$

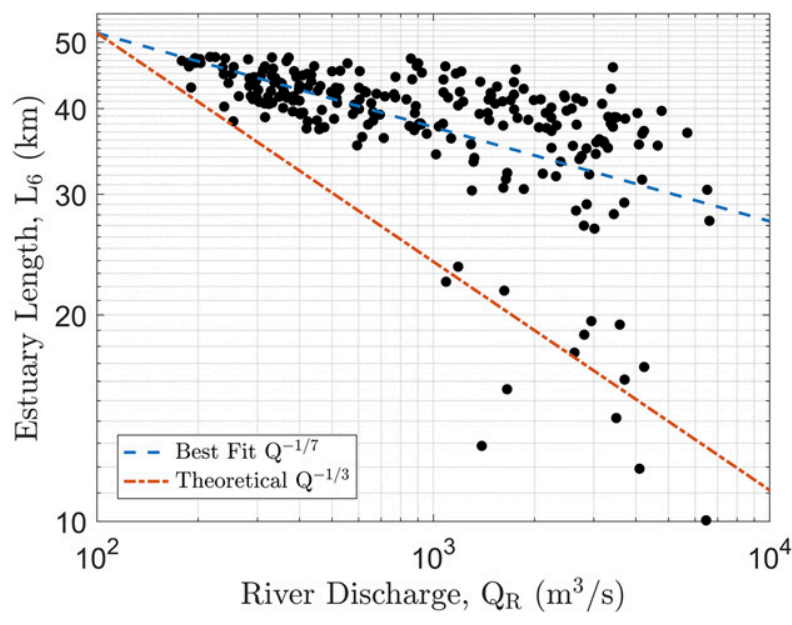

FIG. 3. Estuary length measured from a fixed station (DI) to the 6-PSU isohaline $\left(L_{6}\right)$ based on 14-day averages and plotted with river discharge. Black dots are calculated values from measurements at stations DI, MB, and MP. Here, $L_{6} \sim Q_{R}^{-1 / 7}$ is the best fit line, and $L_{6} \sim Q_{R}^{-1 / 3}$ is the theoretical ideal estuary relationship (note that river discharge and estuary length are shown on a log scale).

where $\gamma$ is a constant (1.22), $\mathrm{Ri}_{c}$ is the critical gradient Richardson number (0.25), $N_{\infty}$ is the buoyancy frequency of the pycnocline, and $\Delta t$ is a characteristic time scale chosen as $3.5 \mathrm{~h}$ based on observations at station $\mathrm{MB}$, consistent with other studies (Chen and Sanford 2009).

\section{Results}

\section{a. Estuary length}

Over the 11 years of observations, river discharge in Mobile Bay (14-day averages) ranged from 200 to $7000 \mathrm{~m}^{3} \mathrm{~s}^{-1}$. The average discharge was $1450 \mathrm{~m}^{3} \mathrm{~s}^{-1}$, and the annual range is shown in Fig. 2. The mean estuary length was $38 \mathrm{~km}$, measured from the mouth of the bay at the DI station (Fig. 1), and is roughly 5 times longer than the tidal intrusion length $(5-10 \mathrm{~km})$. Figure 3 shows the relationship between river discharge and estuary length. The best fit line $Q_{R}^{-1 / 7}$ had a close fit with observations for discharge values $<1000 \mathrm{~m}^{3} \mathrm{~s}^{-1}$. As the discharge increased beyond $1000 \mathrm{~m}^{3} \mathrm{~s}^{-1}$, variability increased between observed lengths and the best fit line. This increased variability had deviations up to $20 \mathrm{~km}$ shorter than the best fit line.

To further examine the increasing variability of observations from the best fit line and the $Q_{R}^{-1 / 7}$ relationship, the estuary length was looked at with respect to changes in cross-sectional area and depth based on $A^{1 / 3} H^{5 / 3}$ from Eq. (1) (defined here as $G=A^{1 / 3} H^{5 / 3}$ ). Since large changes in shape can alter the salinity structure based on volume and gravitational circulation 
associated with depth, the along-channel variability of $G$ was looked at to determine its importance in modifying the relationship between estuary length and discharge. Following Ralston et al. (2008), the $G$ term was normalized by the salinity gradient (termed $\bar{G}$ ) and plotted with respect to $Q_{R}$ (Fig. 4). The $Q_{R}$ showed no relationship to $\bar{G}$, but similar to Fig. 3, there was increasing variability in $\bar{G}$ with increasing river discharge. Changes in estuary shape were not proportional to river forcing and were unable to explain the variability from the ideal $Q_{R}^{-1 / 3}$ relationship.

The changes in length associated with wind were examined by plotting deviations from the best fit line with respect to the wind direction (Fig. 5a), the Wedderburn number from Eq. (7) (Fig. 5b), and the modified horizontal Richardson number from Eq. (10) (Fig. 5c). Figure 5a shows an asymmetry in deviations from the best fit line when plotted against wind direction. Winds blowing down estuary $\left(135^{\circ}-225^{\circ}\right)$ show less variability (ranging from 0 to $10 \mathrm{~km}$ ) and are associated with longer estuary lengths than predicted by the best fit line in Fig. 3. Up-estuary winds $\left(315^{\circ}-45^{\circ}\right)$ had greater variability (ranging from -20 to $10 \mathrm{~km}$ ) and were associated with the largest deviations from the best fit line that shortened the estuary length. This along-channel wind response was also observed with respect to the Wedderburn number shown in Fig. 5b. For the 14-day averages, the majority of the Wedderburn numbers fall below 1 and suggest the dominance of density-driven flow in the bay at these longer time scales. Two relationships can be observed in Fig. 5b: negative Wedderburn numbers (down-estuary winds) have points centralized around $5(5 \mathrm{~km}$ longer than the best fit line in Fig. 3), and positive Wedderburn numbers (up-estuary winds) have a range of deviations decreasing from the best fit line as the Wedderburn number increases. The large negative deviations (from -20 to $-10 \mathrm{~km}$ ) associated with up-estuary winds (shortening the estuary length) show a sharp trend when plotted with the modified horizontal Richardson number (Fig. 5c). Low and negative modified horizontal Richardson number values are associated with deviations less than $-5 \mathrm{~km}$, and a moderate increasing trend can be observed for deviations between -5 and $10 \mathrm{~km}$. These long-term 14-day averages highlight the asymmetries that are associated with the estuary length and along-channel winds from wind direction, modification of shear, and mixing.

\section{b. Salinity flux}

To further understand aspects of the salt balance driving changes in the estuary length, the salinity flux near the center of Mobile Bay was examined from April 2012 to August 2013. Figure 6 summarizes a synoptic

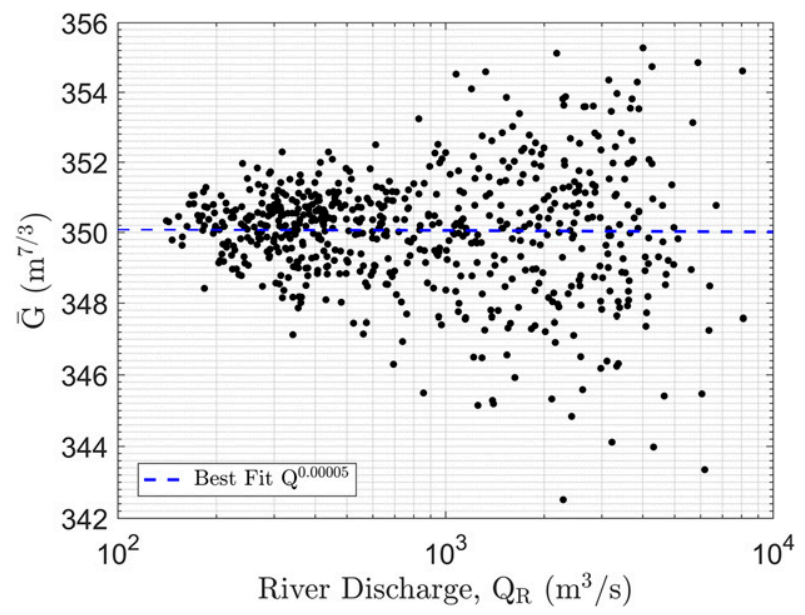

FIG. 4. River discharge relationship to $\bar{G}$, the normalized shape metric used in Ralston et al. (2008), to compare how changes in estuary shape (depth and cross-sectional area) normalized by the salinity gradient change with river discharge (note that river discharge is shown on a log scale).

tidally averaged time series of the river discharge, wind velocity, subtidal shear, subtidal salinity, and salt flux components for the central MB station. Because of gaps in the data record, a shorter time scale of $48 \mathrm{~h}$ was used to average and examine the subtidal salt flux components. Gray vertical bars in Fig. 6 denote gaps in the data that are longer than 7 days. The average discharge during the ADCP deployment was $1900 \mathrm{~m}^{3} \mathrm{~s}^{-1}$, slightly wetter than the historic average.

Winds averaged $4.1 \mathrm{~m} \mathrm{~s}^{-1}$ and were highly variable, apart from the seasonal southwestward winds that dominate from November to March. Figure 6 highlights 27 along-channel wind events based on 48-h periods where the wind is blowing either up $\left(315^{\circ}-50^{\circ}\right)$ or down $\left(130^{\circ}-230^{\circ}\right)$ estuary $80 \%$ of the time. These events are marked by upward- and downward-facing triangles. Ten of the down-estuary events occurred with the seasonal winds from November to March.

Salt flux values were also highly variable, with large positive and negative swings occurring over weekly time scales. Generally $F_{A}$ was the dominant salt flux component but was exceeded by $F_{E} 13 \%$ of the time. Values of $F_{A}$ were both positive and negative. During periods of lower stratification ( $\leq 5 \Delta$ PSU, occurring $37 \%$ of the time), $F_{A}$ was $74 \%$ of the total salt transport, and $F_{E}$ and $F_{T}$ represented only $22 \%$ and $4 \%$, respectively. When stratification was higher ( $>5 \Delta \mathrm{PSU}$, occurring $63 \%$ of the time) $F_{A}$ was less important (57\% of the total flux), and $F_{E}$ increased to $38 \%$ of the total flux. Though increases in discharge and stratification show a strong connection in Figs. $6 \mathrm{a}$ and $6 \mathrm{~d}$, the increases in river discharge had less of an impact on the flux component 

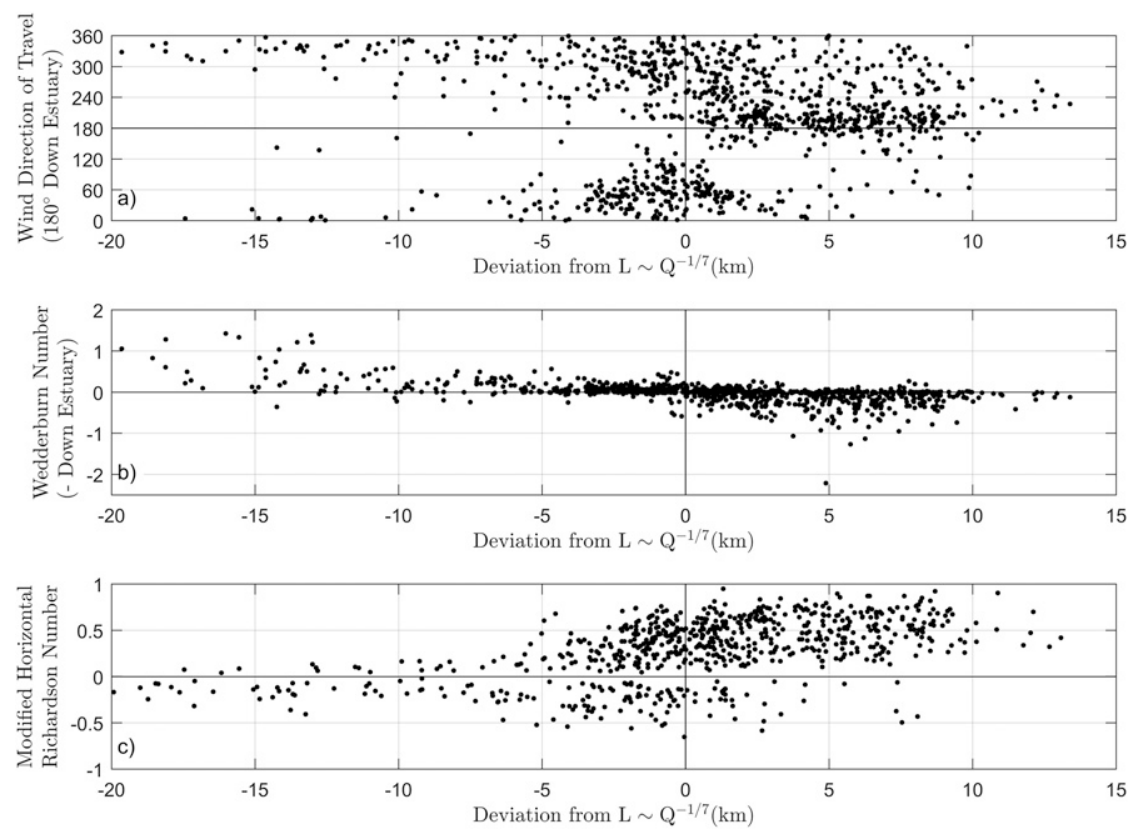

FIG. 5. Deviations from the $L_{6} \sim Q_{R}^{-1 / 7}$ best fit line shown in Fig. 3 are plotted with (a) wind direction $\left(180^{\circ}\right.$ is down-estuary wind), (b) the Wedderburn number (negative Wedderburn numbers are down-estuary winds), and (c) the modified horizontal Richardson number following Chen and Sanford (2009). Positive deviations are estuary lengths (km) longer than the best fit, and negative deviations are shorter than the best fit.

percentages than stratification. For both low $\left(Q_{R}<\right.$ $\left.1450 \mathrm{~m}^{3} \mathrm{~s}^{-1}\right)$ and high discharge $\left(Q_{R}>1450 \mathrm{~m}^{3} \mathrm{~s}^{-1}\right), F_{A}$ was on average $68 \%$ of the total salt transport, and $F_{E}$ was $23 \%$. The standard deviation of these flux components associated with discharge was much larger during low periods (SD of $25 \%$ ) than high periods (SD of $16 \%$ ). This increased standard deviation during low discharge can be seen in Fig. 6e, where large swings in $F_{A}$ occur from April to July 2012, but the average flux component percentages are not changing. River discharge also impacted the magnitude and direction of salt flux. During low discharge, $F_{A}$ values were positive (into the estuary) on average and decreased, becoming larger out of the estuary $F_{A}$ values with increasing discharge. Values of $F_{E}$ were near zero on average during lowdischarge periods and increased (into the estuary) with increasing flow.

To better understand the salt flux, the $F_{E}$ component and total salt flux were plotted with respect to wind direction and the modified horizontal Richardson number (Fig. 7). Three different time periods are highlighted: low discharge occurring from 11 April to 6 July 2012 (blue dots), moderate discharge occurring from 11 April to 6 July 2013 (red dots), and high discharge occurring from 1 December 2012 to 14 March 2013 (yellow dots). The $F_{E}$ in Fig. 7 a shows that during up-estuary wind events $\left(315^{\circ}-45^{\circ}\right)$, the flux was relatively small and, at times, negative on these synoptic time scales. This was a result of gravitational circulation being suppressed by the wind and at some periods reversed, driving low and negative exchange. Down-estuary wind events $\left(135^{\circ}-225^{\circ}\right)$ were more variable. The wind did at times enhance $F_{E}$, producing the asymmetric response seen in Fig. $7 \mathrm{a}$, with the largest values occurring during moderate- and high-discharge periods. The total salt flux in Fig. 7b showed varying trends based on discharge. During moderate- and large-discharge periods, the total flux showed little to no trend with the wind direction. During the low-discharge period, though, salt transport was observed to be greatest into the estuary during down-estuary winds $\left(135^{\circ}-225^{\circ}\right)$. Further evidence of the wind-salt flux interaction can be seen in Figs. $7 \mathrm{c}$ and $7 \mathrm{~d}$, where during the low-discharge period, there is a relationship between the modified horizontal Richardson number and the salt flux. There is a large amount of variability within this trend, and at the moderate- and high-discharge periods, there is no observable trend between the total salt transport and modified horizontal Richardson number (Fig. 7d). For the $F_{E}$ (Fig. 7c) component, at moderate- and highdischarge periods, down-estuary winds do not appear to be modifying the exchange, but the up-estuary winds can play a large role in shutting down and even reversing the exchange during all the discharge periods. 

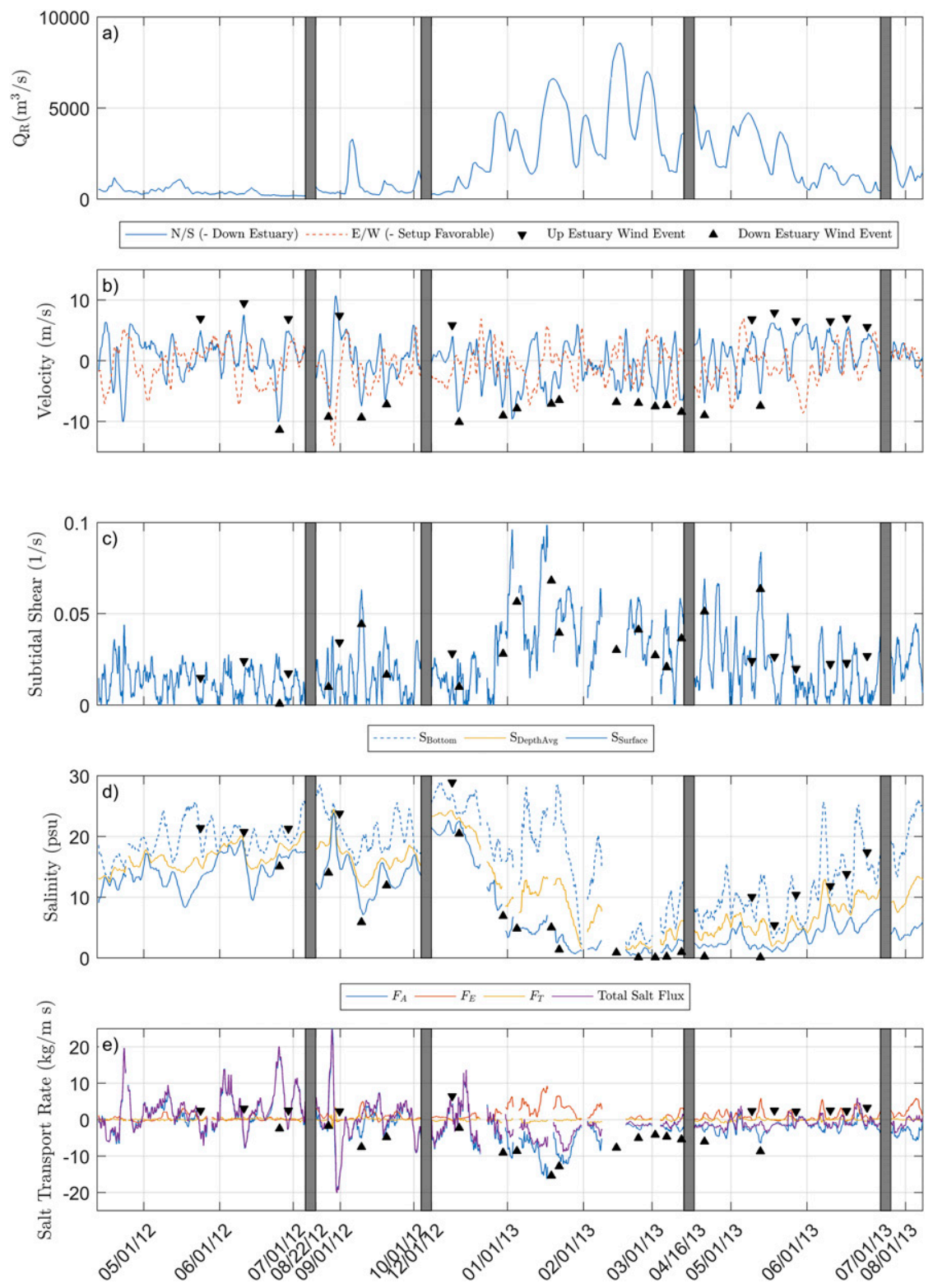

FIG. 6. Time series data from the MB station that highlight (a) the river discharge measured using two upstream USGS stations on the Tombigbee and Alabama Rivers, (b) along- (blue) and across-channel (red) wind velocity, (c) subtidal bulk shear, (d) surface, bottom, and depthaveraged salinity, and (e) salt transport rate for the total (purple), $F_{A}$ (blue), $F_{E}$ (red), and $F_{T}$ (yellow) components. Gray boxes denote data gaps longer than a week, and triangles highlight up-estuary and down-estuary wind events.

To improve the understanding and limitations of these flux measurements, a lateral shear proxy was looked at with respect to river discharge and along-channel winds in Figs. 8 and 9. Continuity-based flow [Eq. (6)] was compared with the ADCP depth-averaged flow to estimate the variability between the two. Figure 8 highlights that as discharge decreases, the flow is more likely to be laterally sheared. The wind's influence on this variability
(Fig. 9) shows that at moderate and high discharge, there is less potential lateral shear associated with wind direction than there is at low discharge. During low discharge and down-estuary winds, velocities at the ADCP are greater into the estuary than those estimated by continuity. This suggests the down-estuary winds are driving set down in the bay, and the resulting return flow to balance this is greatest in the channel and enhances 

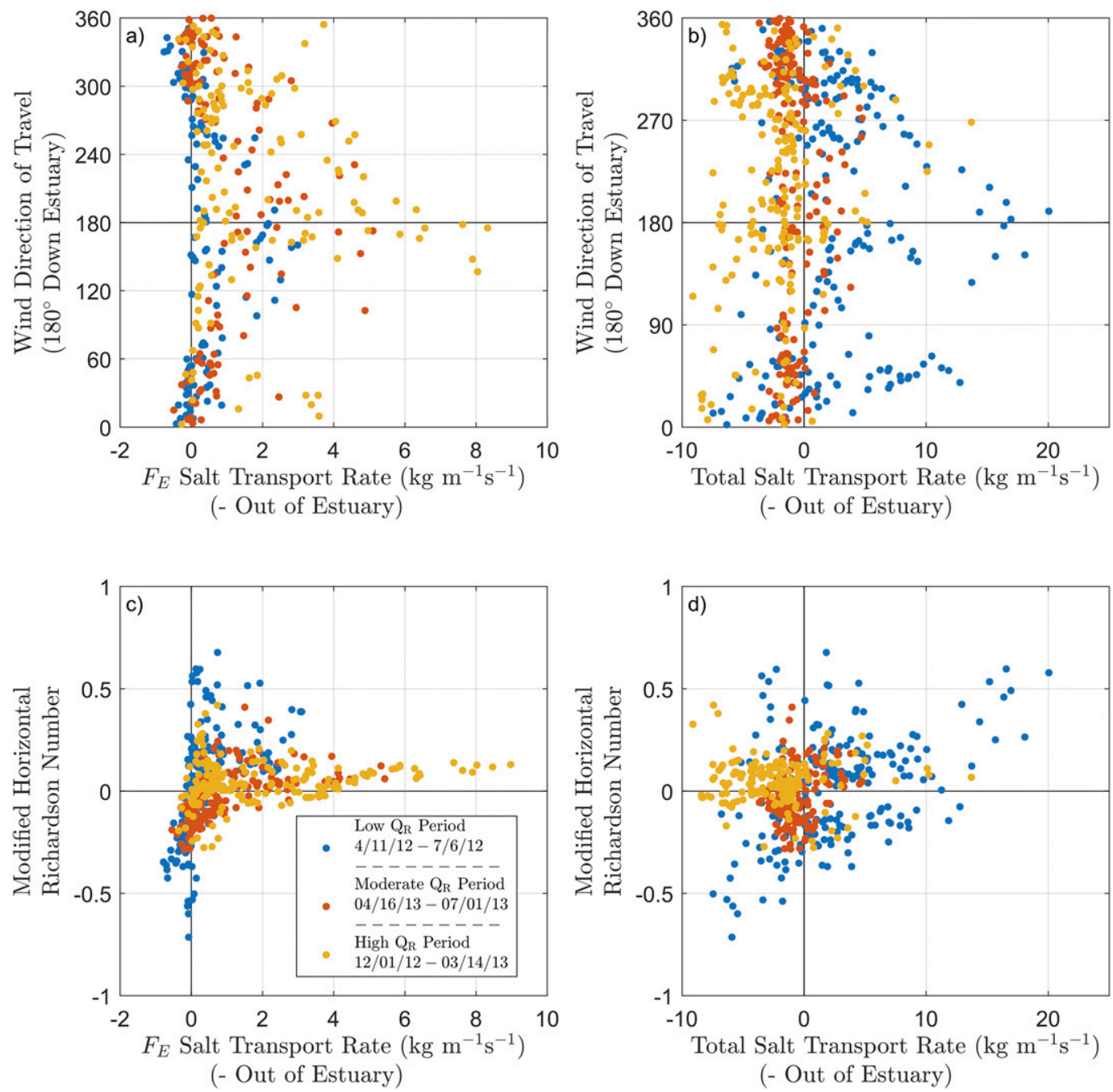

FIG. 7. Changes in (a) salt flux $F_{E}$ and (b) total salt transport rate $\left(F_{A}+F_{E}+F_{T}\right)$ are plotted with wind direction, where $180^{\circ}$ is down estuary. Changes in (c) salt flux $F_{E}$ and (d) total salt transport rate are plotted with the modified horizontal Richardson number. The dataset was broken into three time periods, where discharge was high (yellow), moderate (red), and low (blue), to compare the impact of wind at varying levels of discharge. Note that $F_{E}$ is only solved at the MB station and does not account for any potential lateral shear dispersion in the cross-bay (east-west) direction.

the lateral shear in the estuary during low-discharge periods (i.e., largest negative lateral shear potential values in Fig. 9).

Tropic-equatorial changes had very little impact on any of the salt flux terms. The only observed relationship was that $F_{T}$ tended to be larger during tropic tides, with a salinity flux value of 0.26 , compared to 0.12 during equatorial tides. However, $F_{T}$ was only $7 \%$ of the total flux for all the measured values, though.

Changes in the response time of the salt flux with respect to along-channel winds were evaluated to determine the sensitivity of the results to the low-pass filter and time lags. Sensitivity to the low-pass filter showed a peak in correlation for the total salt flux and alongchannel winds when they were low-pass filtered at $50-60 \mathrm{~h}$. This suggests there is considerable variability at shorter time scales, and longer-duration wind events $(50-60 \mathrm{~h})$ are associated with the changes in salt flux. To investigate the response time of the salt flux, a lag between wind forcing and flux values was also examined (using the 48-h low-pass-filter data). There was no observed lag between $F_{E}$ and along-channel winds, indicating that in this shallow environment, $F_{E}$ responds nearly immediately to the wind, either modifying or inhibiting exchange. A 24-h lag was observed between $F_{A}$ and along-channel winds and indicates the advective 


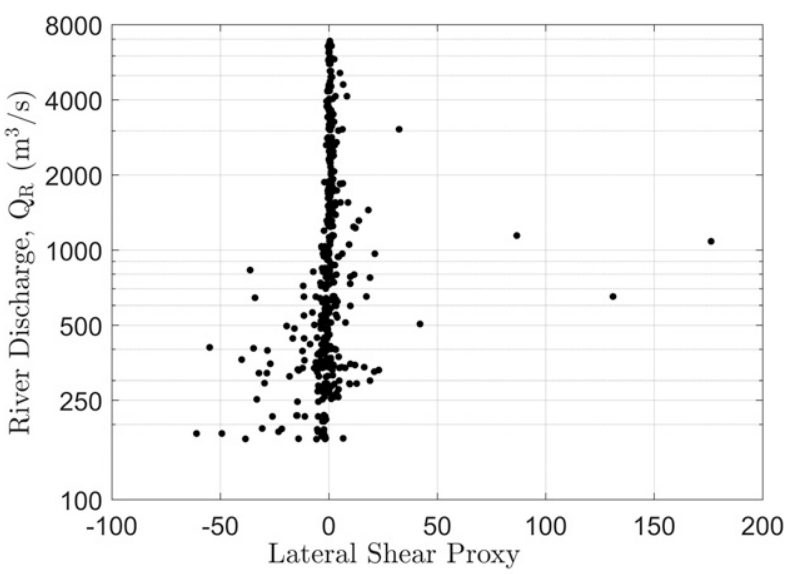

(Precent Difference Between Continuity \& ADCP)

FIG. 8. River discharge plotted with the lateral shear proxy percent difference, where the shear proxy was estimated based on the percent difference between a continuity-based 1D depthaveraged velocity [Eq. (6)] and depth-averaged velocities measured by the ADCP. Negative lateral shear proxy values indicate measurements at the ADCP are less than the theoretical or flowing in the opposite direction (into the estuary). Positive shear proxy values indicate out of the estuary flows at the ADCP are greater than the theoretical flow (note that river discharge is shown on a $\log$ scale).

setup, set down, or mixing impacts on net advection components are slower to occur and drive salt fluxes in the estuary.

\section{c. Shear and stratification}

Conditional averaging was used to compare the wind impact for calm, up-estuary, and down-estuary wind cases at high- and low-discharge periods for the current and salinity structure (Figs. 10, 11). The profiles represent subtidal conditions associated with the corresponding wind and river conditions through averaging over numerous $(>441)$ hourly current profile observations. The current shear showed a strong modification with wind forcing (Fig. 10). During down-estuary wind conditions, the shear was strongly enhanced. Under up-estuary winds, the shear and estuarine exchange flow was inhibited. This shear modification was observed during both high- and low-discharge periods. The impact of the up-estuary winds was strong enough to reverse flow in the upper layer during low-discharge periods. It should be noted that for the last $0.5-\mathrm{m}$ bin off the bottom, the currents all have a linear return to zero. This is a result of the extrapolation scheme used to fit data to a no-slip condition at the seafloor and obtain current data over the entire water column.

The salinity structure showed a decrease in the stratification when the wind is blowing either up or down estuary (Fig. 11). Under calm conditions, the largest

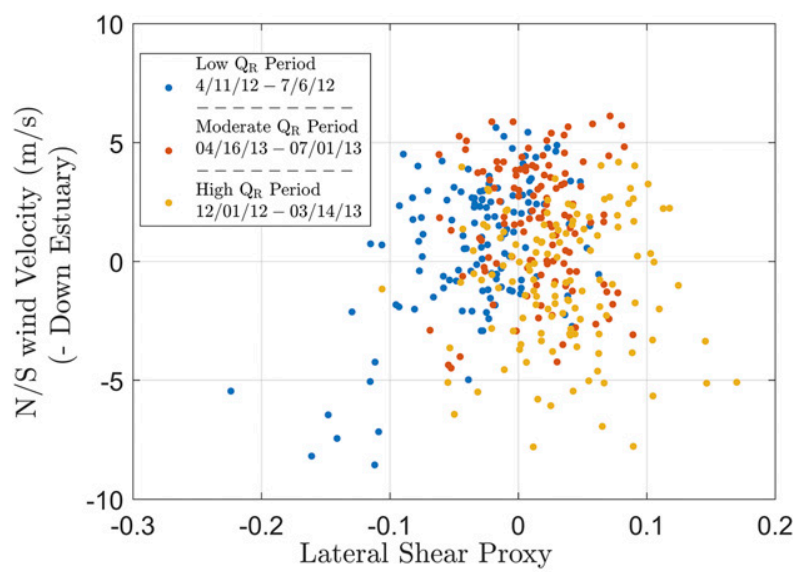

(Difference Between Continuity \& ADCP)

FIG. 9. Lateral shear proxy \{difference between a continuitybased 1D depth averaged velocity [Eq. (6)] and depth-averaged velocities measured by the ADCP $\}$ plotted with along-channel wind velocities for the three discharge periods. Low-discharge periods and negative lateral shear proxy values indicate measurements at the ADCP are less than the theoretical or are flowing in the opposite direction (into the estuary). The largest negative shear proxy values are during low-discharge down-estuary winds, and the largest positive shear proxy values are during high-discharge downestuary winds.

stratification values occurred during high-discharge periods. The time series also highlights that down-estuary wind events tended to maintain the same depthaveraged salinity, and up-estuary wind events reduce the depth-averaged salinity.

\section{Discussion}

\section{a. Estuary length}

Observations from Mobile Bay showed river discharge was the main forcing condition driving the changes in estuary length that were observed over the 14-day averages. The estuary length had a $Q_{R}^{-1 / 7}$ relationship with discharge in this river-dominated, microtidal system (Fig. 3). The discharge to estuary length relationship was less than the expected relationship for an ideal system, $L_{x} \sim Q_{R}^{-1 / 3}$ based on Eq. (1), with a constant mixing parameterization and shape. Understanding the mechanisms of why Mobile Bay is less responsive to discharge then the ideal relationship $\left(L_{x} \sim Q_{R}^{-1 / 3}\right)$ is an important step to improve parameterizing physical forcing conditions in estuaries. The changes in length with respect to river discharge are discussed first to understand this main forcing component in Mobile Bay before discussing the wind impacts on the system.

Mechanisms for the variation have been explained by other researchers. Ralston et al. (2008) found that shape 


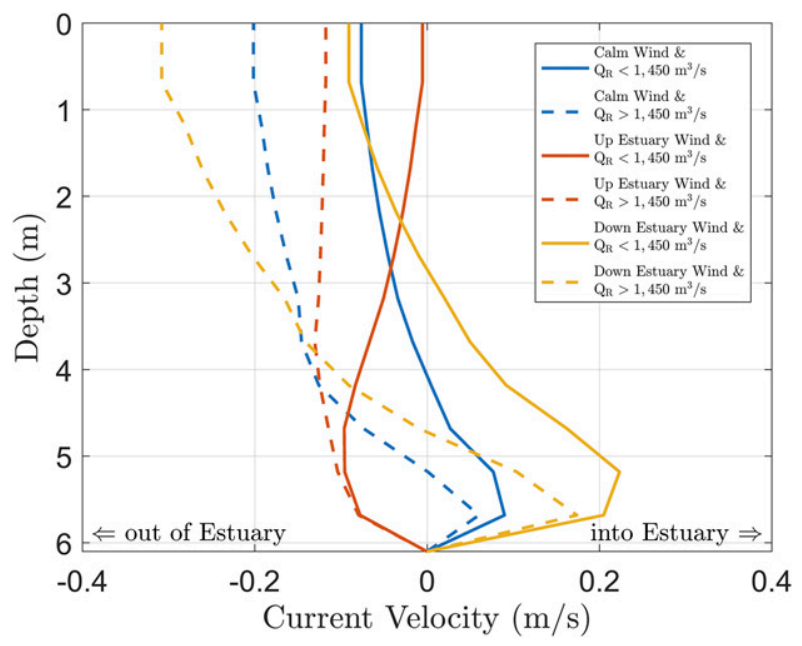

FIG. 10. ADCP current velocities were conditionally averaged based on wind (calm, up estuary, and down estuary) and river discharge ( $>$ mean river discharge and $<$ mean river discharge) to estimate the subtidal current profiles at the MB station during these periods.

was contributing to the $Q_{R}^{-1 / 7}$ relationship in San Francisco Bay. Using the same method, changes in the normalized shape had no relationship to discharge and estuary length for Mobile Bay (Fig. 4). The trends observed in this study were comparable to those measured in the Hudson from that same study. Despite large changes in width, this lack of response is potentially due to weak connectivity between the southeast region of the bay (Bon Secour; Fig. 1) and more central regions of the bay. The limited spatial variability of the sensors in this study prevents any further conclusions to understand these interactions.

Monismith et al. (2002) suggested allowing $\gamma$ to vary with river discharge to account for the $Q_{R}^{-1 / 7}$ relationship with estuary length. Observations of how stratification affects mixing have been made by other researchers. This is accounted for in Eq. (1) through tidal velocity and an effective eddy viscosity relationship in $\gamma$, where the mixing parameterization is defined by Ralston et al. (2008) as

$$
\gamma=a_{0} C_{d} \mathrm{Sc}^{-1 / 3},
$$

where Sc is the Schmidt number, the ratio of eddy viscosity to eddy diffusivity. Monismith et al. (2002) had suggested that as discharge increases, the salt field responds by compressing; this increases exchange, and for systems that remain partially mixed, the response is the theoretical $1 / 3$ fit. If the increased exchange is not mixed at the same rate, then as the flow intensifies, the exchange and the stratification can both intensify and "stiffen" the response of the salt structure in the bay to increasing discharge.

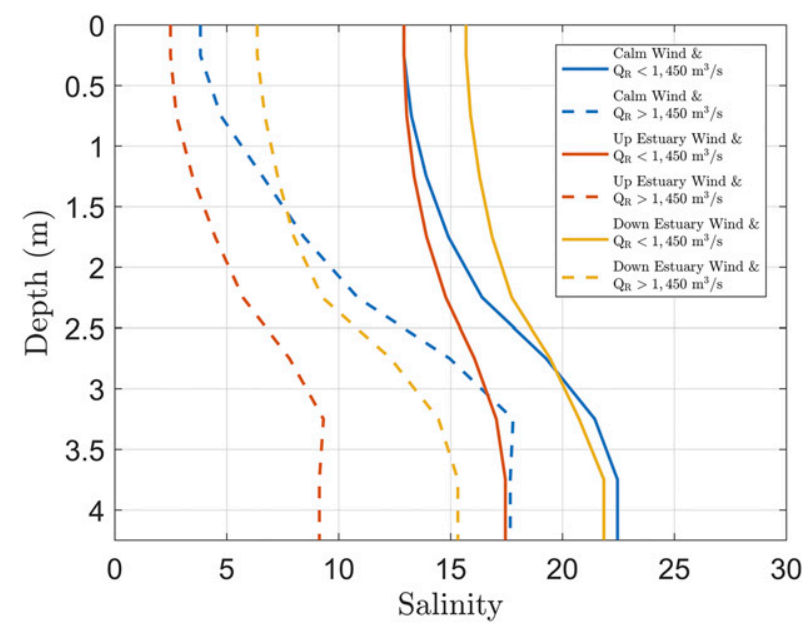

FIG. 11. Vertical salinity values at station MB were averaged based on wind (calm, up estuary, and down estuary) and river discharge ( $>$ mean river discharge and $<$ mean river discharge) to estimate the subtidal vertical salinity profile at the MB station during these conditional periods.

Approaches to determine these changes in $\gamma$ are often evaluated by using $\gamma$ as a tuning parameter for increasing discharge (Monismith et al. 2002) or attempting to parameterize the eddy viscosity and eddy diffusivity. The eddy viscosity used in this study did increase with increasing stratification through changes in the bottom boundary layer. These changes, though, were not enough to reflect the stiffened response highlighted by other researchers. Similar results were observed by Ralston et al. (2008), who found this parameterization in the Hudson had a minor impact on the river discharge to length relationship, and discrepancies between the modeled salinity and observations were greatest during weak tidal mixing and high discharge. Another potential limitation pointed out by Ralston et al. (2008) is that the near-bottom along-estuary gradients can be weak when stratified and underestimate the actual along-estuary gradient due to sloping that occurs in the pycnocline. This limitation may be impacting the bottom boundary layer-based solutions looked at in Mobile Bay. A second limitation is the changes in eddy viscosity are evaluated at a fixed reference point and limit the analysis, compared with a modeled solution or isohaline analysis approach. Though these results are largely qualitative, they reflect previous studies that highlight the importance of the mixing parameterization with increasing river discharge and explain the variation from an ideal system.

\section{b. Salinity flux}

Observations from central Mobile Bay showed river discharge was the main forcing condition driving 
seasonal changes in the total salinity flux. When discharge was low (April-July 2012 in Fig. 6), the total flux was, on average, positive (into the estuary), and when discharge was high (December 2012-March 2013 in Fig. 6), the total salt flux was, on average, negative. Wind and tides played secondary roles in modifying the flux observations, and these changes were more pronounced at low-discharge periods (April-July 2012 in Fig. 6). At event time scales, wind is a dominant forcing condition, driving large changes in the total salinity flux during low-discharge periods (Fig. 7b) and changes in $F_{E}$ at high-, moderate-, and low-discharge periods (Fig. 7b).

Throughout the ADCP deployment, large swings in discharge occurred, varying as much as $5000 \mathrm{~m}^{3} \mathrm{~s}^{-1}$ within the course of a week. This variability in discharge also produced a large amount of variability in the salt flux. Lerczak et al. (2006) found in the Hudson that the system was not reaching a steady state, and this also appears to be the case for Mobile Bay. The flux components never reached a balance and have large positive and negative swings over periods of days.

Comparisons with the salinity flux modeled by Kim and Park (2012) at the mouth of Mobile Bay also showed large changes in the salt flux component's variability. During periods of high stratification, the shear and advective components were balanced over equatorial tides. Kim and Park (2012) observed that when stratification became weak, $F_{A}$ was the dominate term in the total salt flux; this is similar to the observations made in this study. Tidal flux observations made by Kim and Park (2012) at the mouth were more significant than measurements made near the center of the bay. They saw changes in $F_{T}$ that were associated with tropicequatorial changes, and $F_{T}$ was larger than both $F_{A}$ and $F_{E}$ during tropic tides. Near the mouth of the estuary, Lee et al. (2013) measured changes in tidal magnitude that can vary by up to $1 \mathrm{~m} \mathrm{~s}^{-1}$ and are likely associated with this increase of $F_{T}$ at the mouth of the bay. The central site in this study is $22 \mathrm{~km}$ from the mouth of the bay, where $F_{T}$ impacts on transport are likely diminished and reflected in the results. It should be noted, though, that the lateral variability at tidal time scales may also impact $F_{T}$ and were not accounted for in this study.

These changes were measured on synoptic tidally averaged time scales ( $48 \mathrm{~h}$ ) for one point in the bay, and it should be noted that for discharge values less than $750 \mathrm{~m}^{3} \mathrm{~s}^{-1}$, the mean depth-averaged flow is into the estuary $\left(-1 \mathrm{~cm} \mathrm{~s}^{-1}\right)$. Based on continuity and shear proxy estimates, this suggests there is some level of lateral shear across the bay to balance this exchange. This potential shear was observed to decrease with increasing discharge (Fig. 8). Similar results by Webb and Marr (2016) concluded that residence times' spatial heterogeneity tended to decrease with increasing discharge in the bay. This lateral variability in the shear may be another mechanism that is impacting the river discharge relationship with the salinity flux and estuary length in the bay.

The extent to which lateral shear and exchange is being modified in these shallow stratified estuaries needs to be addressed in future research. Measurements of salt flux in the $\mathrm{V}$-shaped, partially mixed Hudson by Lerczak et al. (2006) supported that vertical shear dispersion dominated over lateral. Guo and Valle-Levinson (2008) also found that greater stratification led to more vertically sheared flow structure, but weakly stratified flows were more laterally sheared in the Chesapeake Bay. Surveys collected across Mobile Bay by Ryan et al. (1997) indicate that both lateral and vertical stratification occur baywide, but suggest that the largest lateral changes occur near the mouth of the bay. Noble et al. (1996) noted that in Mobile Bay, the amount of vertical shear varies in the cross-bay direction, but made no point to highlight the potential cross-bay depth-averaged shear as being important in the system. The additional water quality sites used to evaluate the estuary length in this study were examined to provide insight and are, on average, fresher at the edges of the bay when compared to the center. These observations alone, though, were not enough to provide conclusive information on the potential lateral shear dispersion due to the lack of lateral shear measurements, and this warrants further study.

\section{c. Along-channel winds}

Along-channel winds had a range of impacts on the estuary length and salt flux depending on the level of discharge. The largest changes in estuary length occurred during discharge values $>1000 \mathrm{~m}^{3} \mathrm{~s}^{-1}$, and the largest changes in salinity flux occurred during low-discharge values. This response of change in length to winds at higher discharge levels is consistent with other work that has modeled and measured the response of estuary length to spring-neap fluctuations (Lerczak et al. 2009; MacCready 2007). This previous work observed deviations in estuary length not associated with wind, but instead spring-neap changes in tidal velocity and the associated mixing. The observation from Mobile Bay showed little evidence of tropic-equatorial changes like in the previous studies, but the time response mechanism presented in MacCready (2007) is still relevant to the wind forcing. MacCready (2007) derived a hydraulic replacement time $\left.\left[1 / 6\left(L / u_{o}\right)\right]\right)$ to estimate the adjustment time scale associated with how long it takes the estuary length to respond to changes in forcing.

In Fig. 3, the increased variability from the best fit line occurred with estuary lengths of $30-38 \mathrm{~km}$ (for the blue line in Fig. 3), and the calculated adjustment times for 
this length are on the order of $12-90 \mathrm{~h}$, based on methods presented in MacCready (2007). These adjustment time scales $(12-90 \mathrm{~h})$ and periods of increased variability from Fig. 3 show a close connection with the sensitivity analysis, where the salt flux temporal averages peaked with wind averages over 50-60 h. The tropic-equatorial time scale is also within the adjustment time scale for a large number of flows and estuary lengths, but no changes in the estuary length were observed. This may be a limitation of the increased error in estuary length when solved for at temporal scales shorter than 2 weeks.

The observed changes in estuary length that are associated with along-channel winds (Fig. 4) are proposed to be a result of up-estuary winds inhibiting exchange. Winds impacted the salt flux at all discharge levels, but the largest wind-driven changes in length only occurred at higher discharges (due to the faster response time previously noted). The largest changes in salinity flux associated with the wind occurred at low-discharge levels, but the adjustment time scales of the estuary during this low discharge were not small enough to modify the estuary length. These changes in fluxes at low discharge likely enhanced the lateral and vertical shear driving salt up the channel under down-estuary winds, but the events were not long enough in duration to modify the estuary length.

Chen and Sanford (2009) highlighted the wind's role in modifying the strain and mixing balance. Based on their results, the shallow depth in Mobile Bay limits the increase in stratification that can occur with moderate down-estuary winds, but significant shear enhancement does occur. This limited increase in stratification and intense mixing of the water column is likely one reason for the lack of changes observed during down-estuary wind events. The lack of response can be seen in Fig. 5b, where the Wedderburn number parameterizes the dynamics between wind stress and the baroclinic pressure gradient, and in Fig. 5c, where the modified horizontal Richardson number developed by Chen and Sanford (2009) parameterizes stratification increased through shear advection (numerator) with the tidal and wind mixing forces that destratify the water column (denominator). Figures $5 \mathrm{~b}$ and $5 \mathrm{c}$ together highlight that the strong up-estuary winds (positive Wedderburn numbers) and intense wind mixing (small positive and negative modified horizontal Richardson numbers) are associated with the deviations less than $-5 \mathrm{~km}$ from the best fit line. For the down-estuary winds (negative Wedderburn numbers), the trend is less associated with the wind modifying shear, and instead, the slight trend of increasing stratification forces through shear advection (large modified horizontal Richardson numbers) is associated with the larger positive deviations from the best fit line. This limited down-estuary wind response is due to the shallow depth of Mobile Bay. The wind mixing depth, $h_{s}$ in Eq. (10), was on average $1 \mathrm{~m}$ or $1 / 3$ of the average water depth in Mobile Bay, and as a result, this limited the down-estuary wind shear from producing larger positive deviations from the best fit line.

The recovery time of the stratification observed by $\mathrm{Li}$ and $\mathrm{Li} \mathrm{(2011)} \mathrm{is} \mathrm{likely} \mathrm{the} \mathrm{second} \mathrm{mechanism} \mathrm{at} \mathrm{play} \mathrm{in}$ Mobile Bay. Li and Li (2011) demonstrated that stratification took 1-3 weeks longer in their model runs to fully recover from up-estuary wind events. This increased recovery time was explained by the shear and average diffusivity that led to longer response times of the stratification. This suggests the stiffened response associated with river discharge is being "broken" by the mixing associated with the wind stress. The asymmetric response occurs as a result of up-estuary winds inhibiting shear, resulting in longer restratification times to return to the $Q_{R}^{1 / 7}$ best fit. It is a combination of both these mechanisms that impacts the estuary length and the changes observed in Mobile Bay. The results of this study highlight the wind's direct impact through modifying exchange at synoptic time scales and the time it takes the estuary to recover based the asymmetries in the 14-day average estuary length.

Previous research in Mobile Bay has highlighted the importance of wind on estuary dynamics. Early work by Wiseman et al. (1988) found that along-channel wind stress drove surface water in a coherent manner at Main Pass, but they did not observe the periods of higher discharge seen in this study where surface flow was not reversed. Noble et al. (1996) found the current response to wind is dependent on stratification: when stratified, the wind forced currents are highly sheared. This is similar to the observations presented by Guo and Valle-Levinson (2008). Webb and Marr (2016) showed the spatial variability in hydrodynamic time scales varied by as much as $60 \%$ when compared to cases with discharge and tides only. The continuation of this work to improve the understanding of how wind in shallow systems changes estuarine dynamics is important for understanding the asymmetry in the observed changes and the level of importance for wind as a forcing condition.

\section{Summary and conclusions}

The results of this study suggest that the estuary length in Mobile Bay is proportional to $Q_{R}^{-1 / 7}$, and this deviation from the ideal $1 / 3$ power law fit is due to increased stratification with discharge. This increased stratification can lead to changes in mixing and the observed response of the estuary to river forcing. Changes in estuary length were also observed to be modified by 
along-channel winds. These changes in length were based on 14-day averages and suggest the changes in the estuary were on time scales beyond setup and set down in the bay. The proposed mechanism for this change is enhanced mixing from the wind stress breaking the stiffened response of the estuary associated with stratification, and up-estuary winds inhibit shear, delaying the time it takes for stratification to fully recover from upestuary wind events. The observations of salt flux on synoptic time scales show $F_{E}$ is being modified in response to wind forcing. The advective and total salt flux terms were also modified by the wind, predominately at low discharge. This response in the salt flux suggests the lengthening and shortening of the estuary is due to changes in the advective-exchange balance being modified and inhibited by the wind, although improved lateral data are needed to confirm this.

In this shallow, microtidal system, wind can play a large role in modifying the estuary length on scales comparable to the spring-neap changes observed in other systems. Estuary length showed an asymmetric response to wind and was consistent with other work that indicates the recovery time to return to steady state can inhibit exchange. Down-estuary winds modified exchange through shear, but the response was capped by mixing over the shallow depths. Up-estuary winds inhibited shear and mixed the water column, leading to the reduced estuary lengths. This relationship is likely to be important in other shallow stratified systems, where wind mixing can contribute to scales that exceed tidal mixing, and includes other shallow microtidal systems, like those in the Gulf of Mexico and the Mediterranean Sea, and smaller tributaries of large estuaries.

Acknowledgments. Data were collected by the Tech Support Group at the Dauphin Island Sea Lab, including Kyle Weis, Roxanne Robertson, Alan Gunter, Mike Dardeau, Grant Lockridge, Hunter King, Yantzee Hintz, and Laura Linn, and the Alabama Real-time Coastal Ocean Observing System program manager, Renee Collini (data available at www.mymobile.com). Additional data sources were also made available by the Alabama Department of Natural Resources-Marine Resource Division. This research was made possible in part by a grant from the NOAA RESTORE program (NA17NOS4510101). We acknowledge comments provided by the two anonymous reviewers that helped to improve this manuscript.

\section{REFERENCES}

Abood, K. A., 1974: Circulation in the Hudson estuary. Ann. N.Y. Acad. Sci., 250, 39-111, https://doi.org/10.1111/j.17496632.1974.tb43895.x.
Aristizábal, M., and R. Chant, 2013: A numerical study of salt fluxes in Delaware Bay estuary. J. Phys. Oceanogr., 43, 15721588, https://doi.org/10.1175/JPO-D-12-0124.1.

Chant, R. J., W. R. Geyer, R. Houghton, E. Hunter, and J. Lerczak, 2007: Estuarine boundary layer mixing processes: Insights from dye experiments. J. Phys. Oceanogr., 37, 1859-1877, https://doi.org/10.1175/JPO3088.1.

Chen, S.-N., and L. P. Sanford, 2009: Axial wind effects on stratification and longitudinal salt transport in an idealized, partially mixed estuary. J. Phys. Oceanogr., 39, 1905-1920, https:// doi.org/10.1175/2009JPO4016.1.

Garvine, R. W., R. K. McCarthy, and K.-C. Wong, 1992: The axial salinity distribution in the Delaware estuary and its weak response to river discharge. Estuarine Coastal Shelf Sci., 35, 157-165, https://doi.org/10.1016/S0272-7714(05)80110-6.

Geyer, W. R., 1997: Influence of wind on dynamics and flushing of shallow estuaries. Estuarine Coastal Shelf Sci., 44, 713-722, https://doi.org/10.1006/ecss.1996.0140.

Guo, X., and A. Valle-Levinson, 2008: Wind effects on the lateral structure of density-driven circulation in Chesapeake Bay. Cont. Shelf Res., 28, 2450-2471, https://doi.org/10.1016/ j.csr.2008.06.008.

Hetland, R. D., and W. R. Geyer, 2004: An idealized study of the structure of long, partially mixed estuaries. J. Phys. Oceanogr., 34, 2677-2691, https://doi.org/10.1175/JPO2646.1.

Kim, C.-K., and K. Park, 2012: A modeling study of water and salt exchange for a micro-tidal, stratified northern Gulf of Mexico estuary. J. Mar. Syst., 96-97, 103-115, https://doi.org/10.1016/ j.jmarsys.2012.02.008.

Lee, J., B. M. Webb, B. Dzwonkowski, K. Park, and A. ValleLevinson, 2013: Bathymetric influences on tidal currents at the entrance to a highly stratified, shallow estuary. Cont. Shelf Res., 58, 1-11, https://doi.org/10.1016/j.csr.2013.03.002.

Lerczak, J. A., W. R. Geyer, and R. J. Chant, 2006: Mechanisms driving the time-dependent salt flux in a partially stratified estuary. J. Phys. Oceanogr., 36, 2296-2311, https://doi.org/ 10.1175/JPO2959.1.

, and D. K. Ralston, 2009: The temporal response of the length of a partially stratified estuary to changes in river flow and tidal amplitude. J. Phys. Oceanogr., 39, 915-933, https:// doi.org/10.1175/2008JPO3933.1.

Li, Y., and M. Li, 2011: Effects of winds on stratification and circulation in a partially mixed estuary. J. Geophys. Res., 116, C12012, https://doi.org/10.1029/2010JC006893.

MacCready, P., 2007: Estuarine adjustment. J. Phys. Oceanogr., 37, 2133-2145, https://doi.org/10.1175/JPO3082.1.

—, and W. R. Geyer, 2010: Advances in estuarine physics. Annu. Rev. Mar. Sci., 2, 35-58, https://doi.org/10.1146/ annurev-marine-120308-081015.

Monismith, S. G., 1986: An experimental study of the upwelling response of stratified reservoirs to surface shear stress. J. Fluid Mech., 171, 407-439, https://doi.org/10.1017/ S0022112086001507.

, W. Kimmerer, J. R. Burau, and M. T. Stacey, 2002: Structure and flow-induced variability of the subtidal salinity field in northern San Francisco Bay. J. Phys. Oceanogr., 32, 3003-3019, https://doi.org/10.1175/1520-0485(2002)032<3003: $\mathrm{SAFIVO}>2.0 . \mathrm{CO} ; 2$.

Noble, M. A., W. W. Schroeder, W. J. Wiseman Jr., H. F. Ryan, and G. Gelfenbaum, 1996: Subtidal circulation patterns in a shallow, highly stratified estuary: Mobile Bay, Alabama. J. Geophys. Res., 101, 25 689-25 703, https://doi.org/10.1029/ 96JC02506. 
Park, K., C.-K. Kim, and W. W. Schroeder, 2007: Temporal variability in summertime bottom hypoxia in shallow areas of Mobile Bay, Alabama. Estuaries Coasts, 30, 54-65, https:// doi.org/10.1007/BF02782967.

Ralston, D. K., W. R. Geyer, and J. A. Lerczak, 2008: Subtidal salinity and velocity in the Hudson River estuary: Observations and modeling. J. Phys. Oceanogr., 38, 753-770, https:// doi.org/10.1175/2007JPO3808.1.

Ryan, H. F., M. A. Noble, E. A. Williams, W. W. Schroeder, J. R. Pennock, and G. Gelfenbaum, 1997: Tidal current shear in a broad, shallow, river-dominated estuary. Cont. Shelf Res., 17, 665-688, https://doi.org/10.1016/S0278-4343(96) 00053-2.

Schroeder, W. W., and W. J. Wiseman, 1986: Low-frequency shelf-estuarine exchange processes in Mobile Bay and other estuarine systems on the northern Gulf of Mexico. Estuarine Variability, D. Wolfe, Ed., Academic Press, 355-367, https://doi. org/10.1016/B978-0-12-761890-6.50027-7.

, and _-, 1999: Geology and hydrodynamics of Gulf of Mexico estuaries. Biogeochemistry of Gulf of Mexico Estuaries, T. Bianchi, J. Pennock, and R. Twilley, Eds., John Wiley and Sons, 3-28.
S. P. Dinnel, and W. J. Wiseman, 1990: Salinity stratification in a river-dominated estuary. Estuaries, 13, 145-154, https:// doi.org/10.2307/1351583.

Scully, M. E., C. Friedrichs, and J. Brubaker, 2005: Control of estuarine stratification and mixing by wind-induced straining of the estuarine density field. Estuaries, 28, 321-326, https:// doi.org/10.1007/BF02693915.

Stacey, M. T., J. R. Burau, and S. G. Monismith, 2001: Creation of residual flows in a partially stratified estuary. J. Geophys. Res., 106, 17 013-17 037, https://doi.org/10.1029/2000JC000576.

Trowbridge, J., 1992: A simple description of the deepening and structure of a stably stratified flow driven by a surface stress. J. Geophys. Res., 97, 15 529-15 543, https://doi.org/10.1029/ 92JC01512.

Webb, B. M., and C. Marr, 2016: Spatial variability of hydrodynamic timescales in a broad and shallow estuary: Mobile Bay, Alabama. J. Coastal Res., 322, 1374-1388, https://doi.org/ 10.2112/JCOASTRES-D-15-00181.1.

Wiseman, W. J., W. W. Schroeder, and S. P. Dinnel, 1988: Shelfestuarine water exchanges between the Gulf of Mexico and Mobile Bay, Alabama. Larval Fish and Shellfish Transport through Inlets, M. P. Weinstein, Ed., American Fisheries Society, 1-8. 